\title{
Aerosol optical depth retrievals in central Amazonia from a multi-filter rotating shadow-band radiometer calibrated on-site
}

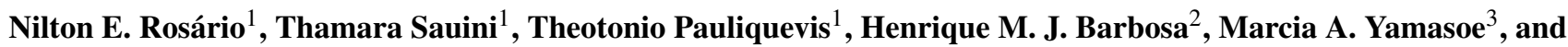 \\ Boris Barja ${ }^{2, a}$ \\ ${ }^{1}$ Departamento de Ciências Ambientais da Universidade Federal de São Paulo, Rua São Nicolau 210, \\ Diadema, SP, CEP 09913-030, Brazil \\ ${ }^{2}$ Instituto de Física da Universidade de São Paulo, Rua do Matão 1371, São Paulo, SP, CEP 05508-090, Brazil \\ ${ }^{3}$ Instituto de Astronomia, Geofísica e Ciencias Atmosféricas, Universidade de São Paulo, \\ Rua do Matão 1226, São Paulo, SP, CEP 05508-090, Brazil \\ ${ }^{a}$ now at: Universidade de Magallanes, Manuel Bulnes 01855, Region de Magallanes y de la Antártica \\ Chilena, Punta Arenas, Chile
}

Correspondence: Nilton E. Rosário (nrosario@unifesp.br)

Received: 21 March 2018 - Discussion started: 30 May 2018

Revised: 22 November 2018 - Accepted: 5 December 2018 - Published: 11 February 2019

\begin{abstract}
Extraterrestrial spectral response calibration of a multi-filter rotating shadow band radiometer (MFRSR) under pristine Amazonian Forest atmosphere conditions was performed using the Langley plot method. The MFRSR is installed in central Amazonia as part of a long-term monitoring site, which was used in the context of the GoAmazon2014/5 experiment. It has been operating continuously since 2011 without regular extraterrestrial calibration, preventing its application to accurate monitoring of aerosol particles. Once calibrated, the MFRSR measurements were applied to retrieve aerosol particle columnar optical properties, specifically aerosol optical depth $\left(\mathrm{AOD}_{\lambda}\right)$ and Ångström exponent (AE), which were evaluated against retrievals from a collocated Cimel Sun photometer belonging to the AErosol RObotic NETwork (AERONET). Results obtained revealed that pristine Amazonian conditions are able to provide MFRSR extraterrestrial spectral response with relative uncertainty lower than $1.0 \%$ in visible channels. The worst estimate (air mass $=1$ ) for absolute uncertainty in $\mathrm{AOD}_{\lambda}$ retrieval varied from $\approx 0.02$ to $\approx 0.03$, depending on the assumption regarding uncertainty for MFRSR direct normal irradiance measured at the surface. The obtained root mean square error $(\mathrm{RMSE} \approx 0.025)$ from the evaluation of MFRSR retrievals against AERONET $\mathrm{AOD}_{\lambda}$ was, in general, lower than estimated MFRSR $\mathrm{AOD}_{\lambda}$ uncertainty, and
\end{abstract}

close to the uncertainty of AERONET field Sun photometers $(\approx 0.02)$.

\section{Introduction}

Aerosol optical depth (AOD) is an important variable for characterizing atmospheric particles' columnar abundance and is also fundamental in estimating their direct radiative forcing in the climate system (Shaw, 1983; Kaufman et al., 2002; Menon, 2004; Satheesh and Srinivasan, 2005). Its relevance is also growing in the context of air quality monitoring from satellites (Hoff and Christopher, 2009; van Donkelaar et al., 2010, 2013). However, the so-called extraterrestrial response calibration (ERC) of the radiometers designed to monitor AOD, for instance Sun tracking and shadow-band radiometers (Holben et al., 1998; Harrison and Michalsky, 1994), is a critical issue in the accuracy of AOD retrievals (O'Neill et al., 2005; Sinyuk et al., 2012; di Sarra et al., 2015). Therefore, regular and adequate calibration of Sun-tracking and shadow-band radiometers dedicated to monitor AOD is vital (Holben et al., 1998; Eck et al., 1999; Michalsky et al., 2001). The ERC consists of the estimation of the solar energy that would be measured by 
the instrument at the top of the atmosphere (TOA) or in hypothetical absence of the atmosphere. It remains one of the most critical calibrations in the accuracy of AOD retrieval (Forgan, 1994; Michalsky et al., 2001; Eck et al., 1999; Chen et al., 2013). The classical way to perform ERC is based on the Langley plot method, for which measurements on high mountaintops, under clean air and stable conditions, are recommended (Shaw et al., 1973; Holben et al., 1998). However, very often, regular trips to very high, clean mountaintops to perform ERC are not possible, either due to the lack of resources or to avoid data collection interruption. Consequently, with the spread of ground-based AOD monitoring networks, on-site calibration based on multiple Langley plots has been successfully adopted elsewhere (Michalsky et al., 2001; Augustine et al., 2008; Rosario et al., 2008; Mazzola et al., 2010; Michalsky and LeBaron, 2013). During the last few decades, Amazonia has been a stage for various intensive and mid- to long-term atmospheric experiments (Avissar et al., 2002; Silva Dias et al., 2002; Andreae et al., 2004; Martin et al., 2016), performing a large number of field measurements, and regularly including ground-based monitoring of AOD. Given the inherent complex logistics that characterize field experiments in Amazonia, regular trips to distant, clean mountaintops to perform ERC of AOD monitoring devices operating inside the forest are a challenge, mainly for long-term sites. Unlike AErosol RObotic NETwork (AERONET) Sun photometers, which have regular calibration logistics supported by NASA (Holben et al., 1998), other ground-based devices for AOD monitoring operating inside Amazonia have to find alternative ways to provide a regular calibration. Multi-filter rotating shadow-band radiometers (MFRSR, Harrison and Michalsky, 1994) have also been deployed recurrently in the Amazon basin to monitor spectral and broadband solar irradiance and AOD during specific seasons (Yamasoe and do Rosario, 2009; Rosario et al., 2009; Yamasoe et al., 2014; Martin et al., 2016), and more recently focusing on mid- and long-term monitoring (Barbosa et al., 2014). An experimental site, located in central Amazonia, and included in the context of the Observations and Modelling of the Green Ocean Amazon (GoAmazon2014/5, Martin et al., 2016), under the reference T0e, is operating since 2011 a MFRSR as part of a set of instruments for performing long-term atmospheric monitoring of convection, radiation, aerosols, and cloud properties in central Amazonia (Barbosa et al., 2014). GoAmazon2014/5 experimental sites range from time point zero (T0) upwind of pollution associated with Manaus, Brazil (Fig. 1), to sites in the midst (T1) and downwind (T2, T3) of the pollution plume (Martin et al., 2016). The MFRSR is being operated at the T0e site since 2011 without performing its ERC, which prevent its application to retrieve AOD. In this context, the question that drives the focus of the present study is as follows: do pristine central Amazonian atmosphere conditions provide successful scenarios for extraterrestrial response calibration? The Amazonian atmosphere under pristine conditions has been denominated as green ocean due to its very low pollution concentration, comparable to remote ocean areas (Roberts et al., 2001; Andreae et al., 2004), which is a fundamental requirement for applying the Langley plot method. To answer the question posed, the present paper describes and discusses methods and results of an effort to calibrate - on site - the cited MFRSR. Its subsequent application for characterizing the AOD variability is evaluated against AOD retrievals from a collocated Cimel Sun photometer from AERONET (Holben et al., 1998) also operated at the T0e site. This paper is organized as follows: Sect. 2 describes the experimental site, provides a brief overview on MFRSR, the Langley plot method, and AOD retrieval theory; Sect. 3 consists of results and discussion; and final remarks are given in Sect. 4.

\section{Experimental site, instruments, and methods}

\subsection{Experimental site T0e}

The T0e site has been operating continuously since February 2011 in central Amazonia, up-wind from Manaus $\left(02^{\circ} 53^{\prime} 27^{\prime \prime} \mathrm{S}, 59^{\circ} 58^{\prime} 12^{\prime \prime} \mathrm{W}\right.$; see Fig. 1), with a set of collocated atmospheric monitoring instruments that includes a MFRSR, a Cimel Sun photometer, and a Raman lidar (Barbosa et al., 2014). The main site goal is to provide long-term characterization of diurnal and seasonal cycles of clouds and convection and the interactions and feedback mechanisms between water vapour, clouds, radiation, and aerosol particles. It was incorporated as part of the GoAmazon2014/5 experiment (Martin et al., 2016) network sites, an international experiment designed to investigate the interactions between the natural Amazonia atmosphere conditions and the air pollution plume from Manaus.

The GoAmazon2014/5 sites were classified from time point zero (T0) upwind of the plume, $\mathrm{T} 1$ in the midst of the plume, T2 just downwind of Manaus, to T3 furthest downwind of Manaus $(70 \mathrm{~km})$. Manaus' pollution plume composition includes nitrogen and sulfur oxides, and high concentrations of submicron aerosol particles and soot (Kuhn et al., 2010), which is consistent with the nature of the local major anthropogenic sources of air pollution: vehicle fleets, power plants, and industrial activities. The study of de Sá et al. (2018) found that the submicron particle composition is dominated by organic material across the sites upwind and downwind of Manaus, independently of the levels of pollution. However, their study pointed out that, among the sites, the absolute mass concentrations of pollutants vary significantly. Average concentrations downwind of Manaus are $100 \%$ to $200 \%$ higher than those upwind. In general, during the wet season, the atmosphere at the T0e site is a clean reference, since its location upwind of Manaus prevents the site of being strongly affected by the city pollution plume. Meanwhile, during the dry season the atmospheric column at T0e, as a large portion of the atmosphere across central 


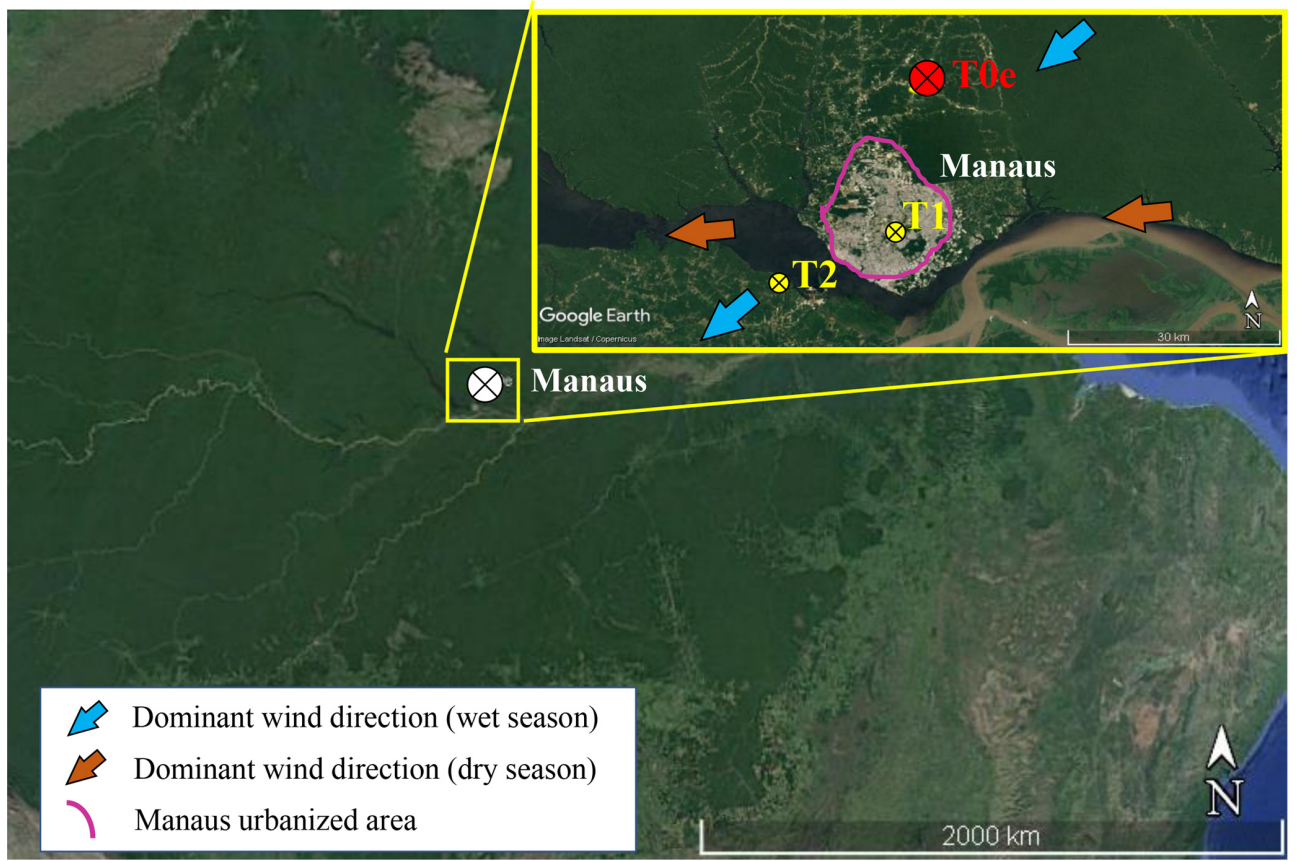

Figure 1. The T0e site location in central Amazonia from an enlarged image showing the site location upwind of Manaus. During the wet season (December to May) the dominant wind direction is from the northeast (blue arrow) and during the dry season (June to November) from the east (brown arrow). The GoAmazon2014/5 experiment sites' relative position to Manaus: T2 is downwind, T1 is in the city, and T0e is upwind of the city (source: Google Earth).

Amazonia eventually is influenced by smoke from biomass burning emissions that occur throughout the Amazon basin.

\subsection{Instruments}

A multi-filter rotating shadow-band radiometer is designed to monitor global horizontal, diffuse horizontal and direct normal solar irradiances in narrow and broadband channels (Harrison et al., 1994). It has been used worldwide to derive columnar aerosol optical properties (Harrison and Michalsky, 1994; Alexandrov et al., 2002; Rosário et al., 2008; Michalsky et al., 2010; Mazzola et al., 2010; Michalsky and LeBaron, 2013), water vapour (Michalsky et al., 1995; Schneider et al., 2010), and cloud optical properties (Min and Harrison, 1996; Kassianov et al., 2011). Direct normal spectral irradiance $\left(I_{\mathrm{DN}, \lambda}\right)$ at the surface, needed to perform AOD retrievals, is obtained via the difference between global-horizontal and diffuse-horizontal irradiances divided by the cosine of the solar zenith angle (Harrison et al., 1994). Once MFRSR angular and spectral responses are properly characterized and the automated shadow-band system adequately adjusted, accuracy in $I_{\mathrm{DN}, \lambda}$ is expected to be comparable to Sun photometers (Harrison et al., 1994). However, once in field, MFRSR filters transmission may suffer degradation with time (Michalsky et al., 2001; Michalsky and LeBaron, 2013), which makes regular ERC critically necessary to keep the accuracy of AOD retrievals. The MFRSR of the present study has been operating with sporadic in- terruptions at T0e providing irradiances measurements at a time interval of $1 \mathrm{~min}$ in five narrow-band channels (415, $500,610,670$, and $870 \mathrm{~nm}$ ) with half-bandwidth of $10 \mathrm{~nm}$ and able to permit AOD retrieval. Given the high cloud cover in central Amazonia, the MFRSR high-frequency measurements are crucial to improve the frequency of AOD retrieval under cloudy sky and, therefore, minimize the AERONET AOD product known bias toward clear-sky condition (Levy et al., 2010).

\subsection{Langley plot calibration and uncertainties}

The Langley plot calibration method is based on LambertBeer law (Shaw, 1983), which describes the attenuation of a monochromatic beam propagating through a medium.

$I_{\mathrm{DN}, \lambda}=f(d) I_{\mathrm{o}, \lambda} \exp ^{-m \tau_{\lambda}}$,

where, considering the full atmospheric column as the medium, $I_{\mathrm{DN}, \lambda}$ is the direct solar spectral irradiance at wavelength $\lambda$ measured at the surface by the MFRSR, $I_{0, \lambda}$ is the solar spectral irradiance that would be measured in the absence of the atmosphere at Earth-Sun mean distance $d_{0}$, $f\left(d_{0}\right)$ is a correction factor related to Earth-Sun distance variation (Iqbal, 1983), and $m$ and $\tau_{\lambda}$ represent the atmosphere relative optical air mass and total optical depth, respectively. Linearizing Eq. (1) by applying the natural logarithms to the both sides of the equation leads to a linear 
relation between $m$ and $\ln \left(I_{\mathrm{DN}, \lambda}\right)$, on which $\tau_{\lambda}$ and $\ln \left(I_{\mathrm{O}, \lambda}\right)$ represent, respectively, the angular and linear coefficients.

$\ln \left(I_{\mathrm{DN}, \lambda}\right)=\ln \left(f(d) I_{\mathrm{o}, \lambda}\right)-m \tau_{\lambda}$

Knowing $\ln \left(I_{\mathrm{DN}, \lambda}\right)$ over a range of $m$, during which the atmosphere remained clean and stable, the least-squares regression method can be applied to provide a linear fit formulation between both variables, where the angular coefficient is the mean atmosphere optical depth, and the linear coefficient represents the case of $m$ equal to zero, a hypothetical absence of atmosphere, from which an estimation of the solar extraterrestrial spectral irradiance $\left(I_{0}, \lambda\right)$ can be made. In the present study, the atmosphere relative optical air mass $(m)$ was calculated as a function of solar zenith angle (SZA) based on Kasten and Young's (1989) formulation and $\ln \left(I_{\mathrm{DN}, \lambda}\right)$ taken from MFRSR direct normal irradiance measurements for 2012 and 2015. As we assumed that both the response variable, $\ln \left(I_{\mathrm{DN}, \lambda}\right)$, and the predictor variable, $m$, are subject to errors, it was applied the least-square regression treatment that consider errors in both adjusted variables (Irvin and Quickenden, 1983). The errors in $\ln \left(I_{\mathrm{DN}}, \lambda\right)$ were obtained through error propagation theory considering the estimate of uncertainty of MFRSR direct normal irradiance in Harrison et al. (1994) $\left(\sigma_{I_{\mathrm{DN}, \lambda}}=2 \%\right)$. Regarding error in the air mass $\left(\sigma_{m}\right)$, we used the method of Tomasi and Petkov (2014), which compared atmospheric air mass results from Kasten and Young (1989) formulation against rigorous calculation and found differences lower than $0.8 \%$. Therefore, we assumed $0.8 \%$ as an estimate of uncertainty in the air mass calculated following Kasten and Young (1989). Following the suggestion of previous studies (Mazzola et al., 2010; Alexandrov et al., 2004), to apply least-square regression we adopted an air mass range from 2.0 to 5.0. For air mass larger than 5.0, high solar energy incident angles, calibration may be affected by the uncertainty of the MFRSR cosine angle correction and the shadow-band correction; meanwhile low air masses, near 1.0, increase the probability of turbulent atmospheric conditions and, therefore, reduction of the optical depth stability (Chen et al., 2013).

The quality of the linear fit derived using least-square regression is highly dependent on optical depth temporal stability, which is more likely to be observed under aerosol background conditions and stable atmosphere. To obtain a set of linear fits that are able to provide high-quality Langley plot calibration samples, for both 2012 and 2015, only morning cases were selected, to avoid the afternoon vigorous convection, and only linear fits with correlation coefficients $\left(R^{2}\right)$ higher than 0.990 were used. This is the minimal value usually obtained for calibration performed on high mountaintops (Schmid and Wehrli, 1995). Also, considering the Schafer et al. (2008) study on AOD climatology across the Amazon basin, only AOD values typical of background conditions were selected. For both years studied, 2012 and 2015, the MFRSR final extraterrestrial spectral response calibration $\left(<I_{0}, \lambda>\right)$ was estimated from the mean of the cor- respondent set of extraterrestrial response calibrations $\left(I_{\mathrm{o}, \lambda}\right)$ obtained from individual Langley plot calibrations. The uncertainties of the derived final calibrations were estimated as the standard error of the mean $\left(\sigma_{I_{0, \lambda}}\right)$. Subsequently, the final calibration results were applied to retrieve $\left(\mathrm{AOD}_{\lambda}\right)$ over the T0e site using the MFRSR. It is worth mentioning that the selection of 2012 and 2015 to answer the question of whether it is possible to obtain accurate extraterrestrial calibration constants derived from the Langley plot method in central Amazonia was based on the evaluation that two independent years, temporally distant, would be adequate to provide findings to support our answer to the question. The temporal distance between the 2 years was meant to detect a potential scenario of filter degradations.

\subsection{Aerosol optical depth $\left(\mathrm{AOD}_{\lambda}\right)$ inversion and uncertainty estimate}

From Eq. (2), the atmospheric total optical depth $\tau_{\lambda}$ can be separated as follows:

$\tau_{\lambda}=\tau_{\mathrm{m}, \lambda}+\mathrm{AOD}_{\lambda}+\tau_{\mathrm{g}, \lambda}$,

where $\tau_{\mathrm{m}, \lambda}$ and $\tau_{\mathrm{g}, \lambda}$ represent, respectively, molecular scattering and gas absorption optical depths. All MFRSR channels are affected by molecular scattering, while gas absorption is highly selective, and therefore affects specific channels. The most relevant influence of gas absorption on MFRSR channels is produced by ozone $\left(\mathrm{O}_{3}\right)$ in the 610 and $670 \mathrm{~nm}$ channels and by nitrogen dioxide $\left(\mathrm{NO}_{2}\right)$ in the $415 \mathrm{~nm}$ channel. Therefore, a combination of Eqs. (3) and (2) leads to the $\mathrm{AOD}_{\lambda}$ retrieval equation

$$
\begin{aligned}
& \operatorname{AOD}_{\lambda}=-\frac{1}{m} \ln \left[\frac{I_{\mathrm{DN}, \lambda}}{f(0)<I_{\mathrm{o}, \lambda}>}\right]-\tau_{\mathrm{m}, \lambda}-\frac{m_{\mathrm{O}_{3}}}{m}-\tau_{\mathrm{O}_{3}, \lambda} \\
& \quad-\tau_{\mathrm{NO}_{2}, \lambda}
\end{aligned}
$$

where $\tau_{\mathrm{m}, \lambda}$ was calculated using the Kasten and Young (1989) formulation as a function of the climatological surface atmospheric pressure. Given its unique vertical distribution, ozone relative optical air mass $\left(m_{\mathrm{O}_{3}}\right)$ was estimated separately based on Staehelin et al. (1995). Ozone $\left(\mathrm{O}_{3}\right)$ and nitrogen dioxide $\left(\mathrm{NO}_{2}\right)$ absorption optical depths over the T0e site were obtained considering their spectral cross section absorption and average column content $\left(\mathrm{O}_{3}=267.6 \pm 5.8\right.$ Dobson units, $\mathrm{NO}_{2}=0.076 \pm 0.012$ Dobson units) over the years between 2011 and 2015, taken from the Ozone Monitoring Instrument (OMI; Levelt et al., 2006) SCanning Imaging Absorption spectroMeter for Atmospheric CHartographY (SCIAMACHY, Bovensmann et al., 1999) products, respectively.

In general, the accuracy of the $\mathrm{AOD}_{\lambda}$ inversion is dominated by the uncertainty in the extraterrestrial response calibration $\left.\left(<I_{\mathrm{O}, \lambda}\right\rangle\right)$ and $\ln \left(I_{\mathrm{DN}, \lambda}\right)$ measurements (Michalsky et al., 2001; Alexandrov et al., 2007; Mazzola et al., 2010). Typically, uncertainties in both terms are at least 1 order of 
magnitude greater than the contributions of the other terms (Mazzola et al., 2010). Considering only the uncertainties in extraterrestrial response calibration $\left(\sigma_{<I_{0, \lambda}>}\right)$ and in $I_{\mathrm{DN}, \lambda}$ measurement $\left(\sigma_{I_{\mathrm{DN}, \lambda}}\right)$, an estimate of uncertainty $\left(\sigma_{\mathrm{AOD}_{\lambda}}\right)$ of the retrieved $\mathrm{AOD}_{\lambda}$ can be evaluated as

$\sigma_{\mathrm{AOD}_{\lambda}}=\sqrt{\left[\frac{1}{m} \frac{\sigma_{I_{\mathrm{O}, \lambda}}}{I_{\mathrm{o}, \lambda}}\right]^{2}+\left[\frac{1}{m} \frac{\sigma_{I_{\mathrm{DN}, \lambda}}}{I_{\mathrm{DN}, \lambda}}\right]^{2}}$,

where $\sigma_{<I_{0}, \lambda}>$, as described, is based on the standard error of the mean of multiple extraterrestrial responses obtained from a set of individual Langley plot calibrations. Evaluation of the uncertainty in $\ln \left(I_{\mathrm{DN}, \lambda}\right)$ is a challenge given its dependency on multiple factors, i.e. shadow-band adjustment, accuracy of the angular response and MFRSR positioning regarding misalignment and tilt (Harrison et al., 1994; Alexandrov et al., 2007). Harrison et al. (1994) estimated MFRSR $\ln \left(I_{\mathrm{DN}, \lambda}\right)$ typical uncertainty to vary between $2 \%$ and $3 \%$. Alexandrov et al. (2007) achieved lower estimation, roughly $1.5 \%$ for all channels. Assuming Harrison et al. (1994) maximum uncertainty (3\%), the final uncertainty in MFRSR $\mathrm{AOD}_{\lambda}$, for all channels, was evaluated for the worst-case scenario, i.e. for unit relative air mass $(m=1)$.

Additionally, considering $\mathrm{AOD}_{\lambda}$ in two spectral channels $\left(\lambda_{1}, \lambda_{2}\right)$ as reference, the spectral dependence of $\mathrm{AOD}_{\lambda}$ was evaluated using the Ångström exponent $\left(\alpha_{\lambda_{1}, \lambda_{2}}\right)$, calculated using the following equation:

$\alpha_{\lambda_{1}, \lambda_{2}}=-\frac{\ln \left[\mathrm{AOD}_{\lambda_{1}} / \mathrm{AOD}_{\lambda_{2}}\right]}{\ln \left[\lambda_{1} / \lambda_{2}\right]}$.

Due to its dependency on aerosol particle size distribution (Eck et al., 1999), $\alpha_{\lambda_{1}, \lambda_{2}}$ can be used as a qualitative indicator to evaluate the predominance of submicrometric (fine particles) or micrometric aerosol particles (coarse mode) in the atmosphere. High values of $\alpha_{\lambda_{1}}, \lambda_{2}$, greater than 2.0, indicate dominance of fine aerosol particles, while values lower than 1.0 are typically related to coarse aerosol particle dominance (Eck et al., 1999). In central Amazonia, for regions upwind of Manaus urban area, such as the T0e site, air masses rich in fine aerosol particles are typically associated with smoke transport from biomass burning regions. Air masses dominated by coarse particle fraction are in general associated with local and regional biogenic and soil particles (Artaxo et al., 1998). Eventually, under favourable atmospheric circulation, air mass containing coarse dust particles transported from the Sahara desert may also affect the T0e site atmospheric column (Koren et al., 2006; Ben-Ami et al., 2010; Moran-Zuloaga et al., 2018).

Retrievals of $\mathrm{AOD}_{\lambda}$ and $\alpha_{\lambda_{1}, \lambda_{2}}$ from MFRSR measurements were validated against AERONET direct Sun products Level 2.0, retrieved by a Cimel Sun photometer also installed at the T0e site. AERONET provides AOD at seven wavelengths $340,380,440,500,670,870$, and $1020 \mathrm{~nm}$, three being coincident with MFRSR wavelengths (500, 670, and $870 \mathrm{~nm}$ ). In order to evaluate the MFRSR $\operatorname{AOD}_{\lambda}$ in the remaining channels, 415 and $610 \mathrm{~nm}$, the Angström exponent from AERONET was used to perform interpolation to derive $\mathrm{AOD}_{\lambda}$ in those channels for the network. Specifically, for comparison purposes, MFRSR $\mathrm{AOD}_{\lambda}$ at $1 \mathrm{~min}$ rate was averaged within a $5 \mathrm{~min}$ interval centred on AERONET Sun photometer retrieval; large standard deviations from the mean, i.e. higher than 0.08 (considering $4 \times$ AERONET field Sun photometer $\mathrm{AOD}_{\lambda}$ uncertainty, which is 0.02 ), were interpreted as potential cloud contamination in MFRSR, and therefore excluded from the analysis. Afterwards, MFRSR results were used to describe and analyse the seasonal variability of columnar aerosol particle optical properties over the T0e site.

The statistical metrics used to compare MFRSR AOD $\left(\right.$ AOD $\left._{M F R}\right)$ with AERONET Sun photometer AOD $\left(\mathrm{AOD}_{\text {Aer }}\right)$, assuming the latter as the reference, are the root mean square error (RMSE), a measure of average deviation from the reference, and bias, a measure of overall bias error or systematic error.

$$
\begin{aligned}
& \text { RMSE }=\sqrt{\frac{1}{N} \sum_{i=1}^{N}\left(\frac{\mathrm{AOD}_{\mathrm{MFR}, i}-\mathrm{AOD}_{\mathrm{Aer}, i}}{\mathrm{AOD}_{\mathrm{Aer}, i}}\right)^{2}} \\
& \text { Bias }=\frac{1}{N} \sum_{i=1}^{N} \frac{\mathrm{AOD}_{\mathrm{MFR}, i}-\mathrm{AOD}_{\mathrm{Aer}, i}}{\mathrm{AOD}_{\mathrm{Aer}, i}}
\end{aligned}
$$

\section{Results}

\subsection{MFRSR Langley plot calibration and uncertainty}

An example of the diurnal cycle of the spectral solar direct normal irradiance measured (20 June 2012) by the MFRSR prone to a successful Langley plot is presented in Fig. 2. In the morning, before vigorous convection initiates, the direct normal irradiance in all channels is characterized by a continuous increase. The suitability of a successful Langley plot is evidenced in the quality of the linear fit achieved, as can be confirmed in Table 1 for the $500 \mathrm{~nm}$ channel. Tables 1 and 2 present for the $500 \mathrm{~nm}$ channels for 2012 and 2015 , respectively, the obtained extraterrestrial response calibrations $\left(\left\langle I_{0}, \lambda\right\rangle\right)$ for each individual Langley plot that met the criteria defined, i.e. $\left(R^{2} \geq 0.990\right)$ and background $\mathrm{AOD}_{550 \mathrm{~nm}}(\leq 0.15)$. The tables with the results for the remaining channels $(415,610,670$, and $870 \mathrm{~nm})$ are presented in the Supplement.

Depending on the year and wavelength, the number of individual Langley calibration constants obtained varied from 14 to 22 , which are figures able to provide consistent statistics for calibration constants according to previous studies (Schmid and Wehrli, 1995; Michalsky et al., 2001; Augustine et al., 2003). Another important aspect to corroborate the quality of the individual Langley plots performed is that more than 60 points per individual Langley plot were ob- 

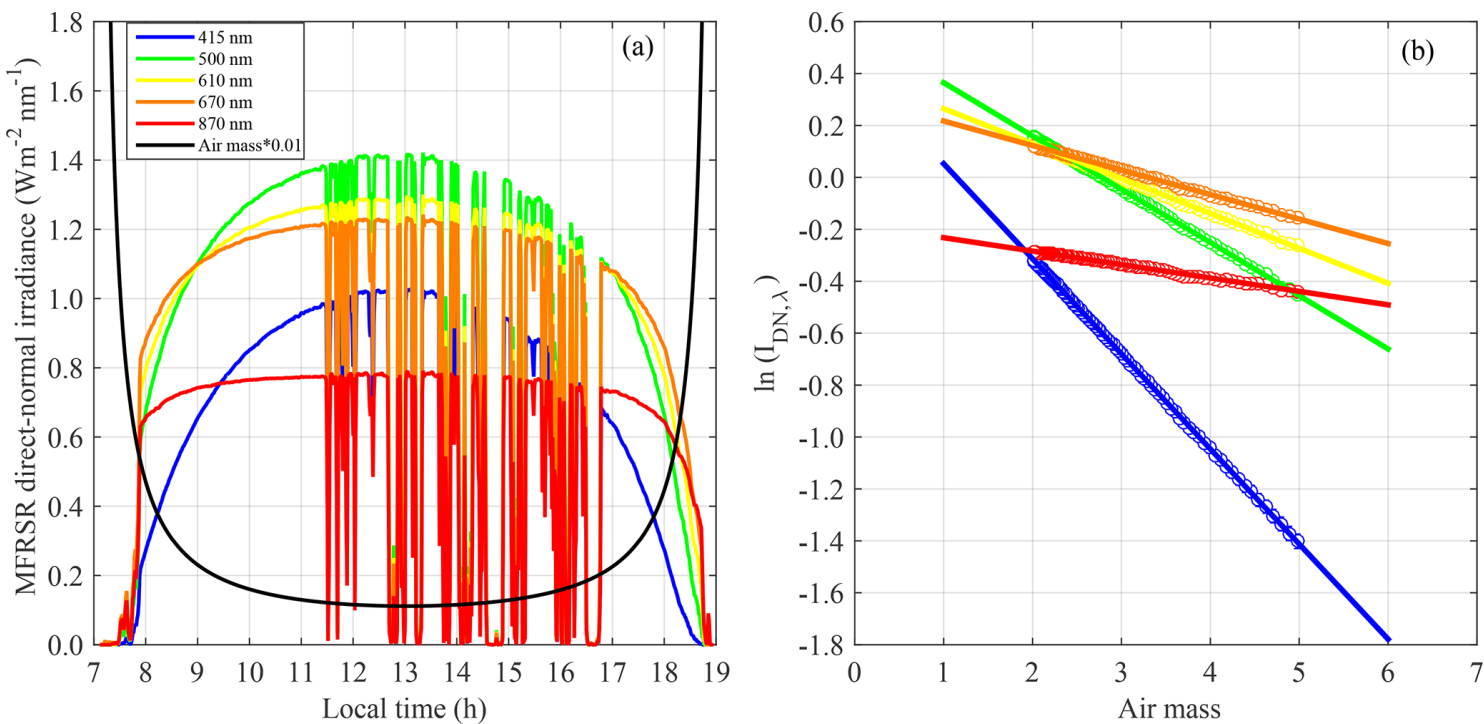

Figure 2. (a) Diurnal cycle of air mass and direct normal spectral solar irradiance measured by the MFRSR operating at the T0e site in central Amazonia. (b) Example of the Langley plot calibration applied to MFRSR spectral irradiance measurements taken during the clear sky period (08:00 to 11:00 local time) of the diurnal cycle shown in (a) (day of measurements: 20 June 2012).

Table 1. Individual extraterrestrial calibration results $\left(I_{\mathrm{O}}, 500 \mathrm{~nm}\right)$ applying the Langley plot technique to measurements of solar direct normal irradiance at $500 \mathrm{~nm}$ from a MFRSR operating at the T0e site in central Amazonia for 2012. The individual uncertainty $\left(\sigma_{I_{\mathrm{o}}, 500 \mathrm{~nm}}\right)$ used to obtain the relative error $\left(\sigma_{I_{0}, 500 \mathrm{~nm}}(\%)\right)$ was estimated from the intercept and its respective uncertainty $\left(\sigma_{\text {intercept }}\right)$ derived from the leastsquare regression method.

\begin{tabular}{lcccccccc}
\hline Date & Slope & $\sigma_{\text {slope }}$ & Intercept & $\sigma_{\text {intercept }}$ & $I_{\mathrm{O}, 500 \mathrm{~nm}}$ & $\sigma_{I_{\mathrm{o}, 50 \mathrm{~nm}}}$ & $R^{2}$ & $N$ \\
\hline 17 May 2012 & -0.2426 & 0.0016 & 0.5709 & 0.0043 & 1.814 & 0.434 & -0.9992 & 63 \\
16 Jun 2012 & -0.2450 & 0.0019 & 0.6058 & 0.0055 & 1.895 & 0.549 & -0.9939 & 64 \\
17 Jun 2012 & -0.2237 & 0.0016 & 0.5560 & 0.0046 & 1.803 & 0.464 & -0.9990 & 61 \\
20 Jun 2012 & -0.2117 & 0.0015 & 0.5846 & 0.0043 & 1.856 & 0.434 & -0.9992 & 64 \\
21 Jun 2012 & -0.2261 & 0.0017 & 0.5722 & 0.0047 & 1.834 & 0.474 & -0.9996 & 65 \\
2 Jun 2012 & -0.2265 & 0.0018 & 0.5362 & 0.0050 & 1.769 & 0.501 & -0.9995 & 71 \\
25 Jun 2012 & -0.2585 & 0.0019 & 0.6461 & 0.0055 & 1.975 & 0.546 & -0.9992 & 78 \\
3 Jul 2012 & -0.2493 & 0.0020 & 0.5848 & 0.0058 & 1.858 & 0.577 & -0.9978 & 61 \\
4 Jul 2012 & -0.2436 & 0.0019 & 0.6060 & 0.0054 & 1.898 & 0.542 & -0.9998 & 63 \\
8 Jul 2012 & -0.2430 & 0.0020 & 0.5668 & 0.0058 & 1.824 & 0.581 & -0.9996 & 64 \\
11 Jul 2012 & -0.2420 & 0.0021 & 0.5456 & 0.0059 & 1.785 & 0.590 & -0.9995 & 62 \\
1 Aug 2012 & -0.2616 & 0.0021 & 0.5843 & 0.0058 & 1.848 & 0.580 & -0.9997 & 64 \\
2 Aug 2012 & -0.2401 & 0.0020 & 0.5221 & 0.0055 & 1.736 & 0.549 & -0.9920 & 62 \\
3 Aug 2012 & -0.2775 & 0.0021 & 0.6313 & 0.0058 & 1.935 & 0.584 & -0.9912 & 65 \\
4 Aug 2012 & -0.2359 & 0.0017 & 0.5751 & 0.0048 & 1.829 & 0.482 & -0.9991 & 62 \\
6 Aug 2012 & -0.2880 & 0.0025 & 0.5561 & 0.0070 & 1.793 & 0.700 & -0.9987 & 63 \\
21 Dec 2012 & -0.2658 & 0.0016 & 0.6294 & 0.0042 & 1.815 & 0.418 & -0.9996 & 63 \\
\hline
\end{tabular}

tained, when 20 is suggested as a minimum to obtain good results (Augustine et al., 2003). It is also worth mentioning that the slopes derived from the Langley plot and presented in Tables 1 and 2 represent the daily average of total atmospheric optical depth (including molecular, gaseous absorption, and aerosol optical depths). Mean molecular and ozone absorption optical depth in central Amazonia in the visible spectrum are $\approx 0.14$ and $\approx 0.01$, respectively. There- fore, assuming these typical values, the subtraction of ozone and molecular optical depth from the total atmospheric optical depth (slopes) would result in daily mean AOD values in the range of $0.05-0.15$, which is typically observed in the Amazonian background atmosphere (Schafer et al., 2008).

The final extraterrestrial response estimations, $\left\langle I_{0, \lambda}\right\rangle$, for both years and all channels, based on average of all individual Langley plot calibrations, are presented in Table 3 
Table 2. Individual extraterrestrial calibration results $\left(I_{\mathrm{O}}, 500 \mathrm{~nm}\right)$ applying the Langley plot technique to measurements of solar direct normal irradiance at $500 \mathrm{~nm}$ from a MFRSR operating at the T0e site in central Amazonia for 2015. The individual uncertainty $\left(\sigma_{I_{0}, 500 \mathrm{~nm}}\right)$ used to obtain the relative error $\left(\sigma_{I_{0}, 500 \mathrm{~nm}}(\%)\right)$ was estimated from the intercept and its respective uncertainty $\left(\sigma_{\text {intercept }}\right)$ derived from the leastsquare regression method.

\begin{tabular}{lcccccccc}
\hline Date & Slope & $\sigma_{\text {slope }}$ & Intercept & $\sigma_{\text {intercept }}$ & $I_{\mathrm{O}, 500 \mathrm{~nm}}$ & $\sigma_{I_{\mathrm{o}, 500 \mathrm{~nm}}}$ & $R^{2}$ & $N$ \\
\hline 19 Feb 2015 & -0.2045 & 0.0014 & 0.5723 & 0.0041 & 1.734 & 0.412 & -0.9959 & 62 \\
27 Mar 2015 & -0.2335 & 0.0015 & 0.5957 & 0.0039 & 1.809 & 0.395 & -0.9941 & 69 \\
4 Jun 2015 & -0.2787 & 0.0021 & 0.6436 & 0.0058 & 1.963 & 0.583 & -0.9923 & 68 \\
24 Jun 2015 & -0.1900 & 0.0013 & 0.5545 & 0.0039 & 1.802 & 0.394 & -0.9996 & 63 \\
1 Jul 2015 & -0.2301 & 0.0016 & 0.6247 & 0.0048 & 1.933 & 0.478 & -0.9989 & 62 \\
2 Jul 2015 & -0.2039 & 0.0015 & 0.5530 & 0.0043 & 1.800 & 0.433 & -0.9995 & 62 \\
6 Jul 2015 & -0.2397 & 0.0019 & 0.6022 & 0.0054 & 1.890 & 0.542 & -0.9979 & 61 \\
10 Jul 2015 & -0.2513 & 0.0019 & 0.6256 & 0.0055 & 1.934 & 0.546 & -0.9988 & 61 \\
11 Jul 2015 & -0.2487 & 0.0019 & 0.6169 & 0.0056 & 1.917 & 0.556 & -0.9996 & 61 \\
12 Jul 2015 & -0.2634 & 0.0022 & 0.5949 & 0.0063 & 1.876 & 0.634 & -0.9993 & 61 \\
15 Jul 2015 & -0.2896 & 0.0026 & 0.6070 & 0.0074 & 1.898 & 0.745 & -0.9994 & 61 \\
28 Jul 2015 & -0.2606 & 0.0020 & 0.6344 & 0.0056 & 1.945 & 0.555 & -0.9982 & 62 \\
29 Jul 2015 & -0.2496 & 0.0021 & 0.5611 & 0.0059 & 1.807 & 0.585 & -0.9901 & 62 \\
30 Jul 2015 & -0.2406 & 0.0018 & 0.5912 & 0.0051 & 1.862 & 0.510 & -0.9964 & 62 \\
1 Aug 2015 & -0.2500 & 0.0019 & 0.6162 & 0.0054 & 1.908 & 0.536 & -0.9954 & 62 \\
2 Aug 2015 & -0.2907 & 0.0024 & 0.6385 & 0.0066 & 1.950 & 0.657 & -0.9983 & 62 \\
7 Aug 2015 & -0.2535 & 0.0018 & 0.6151 & 0.0051 & 1.902 & 0.508 & -0.9997 & 64 \\
23 Aug 2015 & -0.2652 & 0.0018 & 0.6047 & 0.0048 & 1.870 & 0.482 & -0.9987 & 69 \\
5 Sep 2015 & -0.2623 & 0.0018 & 0.5373 & 0.0044 & 1.737 & 0.438 & -0.9983 & 74 \\
9 Sep 2015 & -0.2411 & 0.0014 & 0.6266 & 0.0038 & 1.895 & 0.376 & -0.9996 & 75 \\
22 Sep 2015 & -0.2825 & 0.0018 & 0.5998 & 0.0045 & 1.831 & 0.454 & -0.9992 & 75 \\
\hline
\end{tabular}

along with the standard error from the mean as the uncertainty $\left(\sigma_{<I_{0, \lambda}>}\right)$ and sample number $(N)$ for 2012 and 2015 . The relative uncertainty among the channels varied from $0.7 \%(870 \mathrm{~nm})$ to $1.0 \%(415 \mathrm{~nm})$ in 2012 , and from $0.4 \%$ $(870 \mathrm{~nm})$ to $1.0 \%(415 \mathrm{~nm})$ in 2015 , which is surprisingly satisfactory for conditions diverse from those that are recommended (clean mountaintops). Additionally, alternative final extraterrestrial response estimations were calculated based on the median of the set of individual Langley plot calibrations. In general, the differences between median and mean based final extraterrestrial response estimations were less than $1 \%$, which would result in AOD differences lower than 0.01 , i.e. half of the typical uncertainty of AOD derived from AERONET field Sun photometer measurements. In our case, extraterrestrial response estimations based on mean were consistent with estimations based on median; therefore, we used mean based values as a reference for estimating MFRSR AOD. Optional techniques may be applied to derive extraterrestrial response calibrations; Michalsky et al. (2001) used Forgan's (1988) ratio Langley technique, based on ratioing values of individual Langley plot calibrations of the $500 \mathrm{~nm}$ channel to those of the $860 \mathrm{~nm}$ channel, to select best individual Langley plot calibration, in order to improve the final extraterrestrial response estimations. In the current study, the lower stability of the $870 \mathrm{~nm}$ channel prevents applying the method of Michalsky et al. (2001). Regarding the relative difference $(-0.4 \%)$ between mean calibration constants de- rived for the 2 years, the difference for the $415 \mathrm{~nm}$ channel is not statistically significant, suggesting that between 2012 and 2015 the correspondent transmission filter did not suffer relevant degradation. Meanwhile, a drift of $4.8 \%$ was observed for the $870 \mathrm{~nm}$ channel, an indication of the lower stability of its transmission filter. The remaining channel $(500,613$, $670 \mathrm{~nm}$ ) calibrations are constant, the opposite of the $870 \mathrm{~nm}$ channel, which presented a positive trend between the 2012 and 2015 calibrations. However, given the values of the uncertainty $\left(\sigma_{<I_{0, \lambda}>}\right)$ in their calibration constants, we are not able to attest statistically that the 500,613 , and $670 \mathrm{~nm}$ channels have suffered degradation.

Concerning the seasonal dependence seen in extraterrestrial response calibration from other MFRSRs (Michalsky et al., 2001), we were not able to provide an evaluation since most of the individual Langley plots performed consisted of days in the dry season (see Tables 1 and 2). Outside of the dry season, mainly during the central Amazonian wet season, the high frequency of clouds precludes the favourable atmospheric conditions required to perform the Langley plot method. Nonetheless, a lack of seasonal dependence is very likely since the temperature of central Amazonia is rather stable throughout the year.

Considering the estimation uncertainties in the obtained extraterrestrial calibration constant $(0.4 \%-1.0 \%)$, and the Harrison et al. (1994) maximum uncertainty (3\%) for MFRSR $I_{\mathrm{DN}, \lambda}$ measurements, accordingly to the error prop- 
Table 3. MFRSR final extraterrestrial calibration estimates for the years 2012 and 2015 based on the mean $\left(<I_{0}, \lambda>\right.$ mean $)$ results and median $\left(<I_{0}, \lambda>_{\text {median }}\right)$ of individual Langley plot calibration from Tables 1, 2 and tables in the Supplement. The uncertainty estimation $\left(\sigma_{<I_{0}, \lambda}>\right)$ is based on the correspondent standard error of the average.

\begin{tabular}{|c|c|c|c|c|c|c|c|c|}
\hline \multirow[t]{2}{*}{ Channels } & \multicolumn{4}{|c|}{2012} & \multicolumn{4}{|c|}{2015} \\
\hline & $N$ & $<I_{\mathrm{o}, \lambda}>_{\text {mean }}$ & $\sigma_{<I_{0, \lambda}>}$ & $<I_{\mathrm{O}, \lambda}>_{\text {median }}$ & $N$ & $<I_{\mathrm{o}, \lambda}>_{\text {mean }}$ & $\sigma_{<I_{0}, \lambda}>$ & $<I_{\mathrm{O}, \lambda}>_{\text {median }}$ \\
\hline $415 \mathrm{~nm}$ & 21 & 1.586 & $0.015(1.0 \%)$ & 1.586 & 22 & 1.579 & $0.017(1.0 \%)$ & 1.582 \\
\hline $500 \mathrm{~nm}$ & 17 & 1.839 & $0.015(0.8 \%)$ & 1.829 & 21 & 1.870 & $0.015(0.8 \%)$ & 1.890 \\
\hline $613 \mathrm{~nm}$ & 14 & 1.545 & $0.010(0.7 \%)$ & 1.537 & 17 & 1.572 & $0.011(0.7 \%)$ & 1.592 \\
\hline $670 \mathrm{~nm}$ & 15 & 1.416 & $0.010(0.7 \%)$ & 1.405 & 18 & 1.433 & $0.008(0.6 \%)$ & 1.443 \\
\hline $870 \mathrm{~nm}$ & 15 & 0.842 & $0.008(0.9 \%)$ & 0.846 & 20 & 0.802 & $0.003(0.4 \%)$ & 0.804 \\
\hline
\end{tabular}

agation analysis (Eq. 6), the worst estimation (i.e. for unit air mass) for our absolute uncertainty in $\mathrm{AOD}_{\lambda}$ is $\approx 0.03$, which is comparable with uncertainty of $\mathrm{AOD}_{\lambda}$ retrieved from AERONET field Sun photometer measurements $(\approx$ 0.02, Eck et al., 1999). However, if a lower uncertainty in $I_{\mathrm{DN}, \lambda}$ is assumed, for instance $1.5 \%$ (as suggested by Alexandrov et al., 2007), it would reduce MFRSR $\mathrm{AOD}_{\lambda}$ uncertainty from $\approx 0.03$ to $\approx 0.02$.

In general, perfect linear Langley plots are associated with stable AOD; however, it is possible that not all nearly linear Langley plots are able to provide correct calibration. Air mass assumption, mainly regarding aerosol particle air mass (Schmid and Wehrli, 1995), instrument-induced artefacts, and the shadow-band system alignment (Chen et al., 2013), may contribute to error in calibration. These influences are all challenging to estimate. Therefore, taking the mean (or median) of a set of individual Langley plot calibrations as the estimate for the final calibration constant, along with the comparison of the AOD results with AERONET Sun photometer retrievals, should provide a good reference to evaluate the quality of the calibration constant obtained. The results obtained for RMSEs derived from the comparison between MFRSR retrievals and AERONET Sun photometer AOD are lower than the estimated uncertainty for MFRSR $\mathrm{AOD}_{\lambda}$ retrievals (i.e. $\approx 0.02-\approx 0.03$, depending on the $I_{\mathrm{DN}, \lambda}$ uncertainty assumed, $1.5 \%$ or $3 \%$ ) and just above the maximum uncertainty for the AERONET field instrument $(\approx 0.02)$, demonstrating that, in spite of eventual error associated with assumption made during the Langley plot application, the final derived constants are able to provide reliable AOD retrievals.

\subsection{Aerosol optical depth $\left(\mathrm{AOD}_{\lambda}\right)$ inversion and uncertainty estimate}

Once the MFRSR channel's final extraterrestrial response calibration was determined, direct normal irradiance measurements taken along 2012 and 2015 were applied to retrieve $\mathrm{AOD}_{\lambda}$ and to calculate the Ångström exponent. Figure 3 illustrates, for a specific day (22 November 2012), results of cloud screening and a comparison between the diurnal variability of $\mathrm{AOD}_{\lambda}$ from the MFRSR and the AERONET Sun photometer. The cloud screening criteria captured the majority of contaminated measurements, but a few suspicious remaining points are likely related to subvisible and optically thin cirrus. Using lidar measurements performed at the T0e site, Gouveia et al. (2017) showed that the frequency of subvisible cirrus (optical depth $<0.03$ ) in central Amazonia can be as high as $42 \%$, while for thin cirrus $(0.03<$ optical depth $<0.3)$ it can be as high as $38 \%$. Therefore, both MFRSR and Cimel operational AOD retrievals are exposed to the influence of this subvisible and thin cirrus. A more conservative cloud screening algorithm would remove a significant amount of cloud-free cases, as seems to be the case for AERONET Sun photometer retrievals. The intercomparison showed the consistency of MFRSR retrievals regarding $\mathrm{AOD}_{\lambda}$ diurnal variability. It is worth emphasizing the higher frequency of MFRSR retrieval during the afternoon when compared with the AERONET product. This is a critical aspect regarding the representativity of $\mathrm{AOD}_{\lambda}$ diurnal variation in regions marked by a strong diurnal cycle of convection and cloud cover such as central Amazonia. The MFRSR 1 min frequency is expected to improve the statistic of AOD under cloudy conditions, since the current AERONET Sun photometer statistics are recognized to be biased toward cloudless sky conditions (Levy et al., 2010).

A comparison focusing on seasonal variability was also performed. Figure 4 presents the 2012 seasonal variability of $\mathrm{AOD}_{500 \mathrm{~nm}}$ and $\alpha_{415 / 670 \mathrm{~nm}}$ over the T0e site, as seen by the MFRSR (based on a $1 \mathrm{~min}$ time resolution) and the AERONET Sun photometer. When all MFRSR instantaneous retrievals are analysed against the AERONET Sun photometer AOD there is an apparent overestimation of AOD and underestimation of the Angström exponent (AE). However, when analysing only coincident retrievals in time from both the MFRSR and the AERONET Sun photometer, the AOD and most of AE results are consistent. Therefore, the apparent higher AOD retrievals and low AE seen in MFRSR results are related to the period during which the AERONET AOD product does not provide retrieval. MFRSR retrievals were able to consistently represent the major seasonal features. From March to June, central Amazonia presents its 

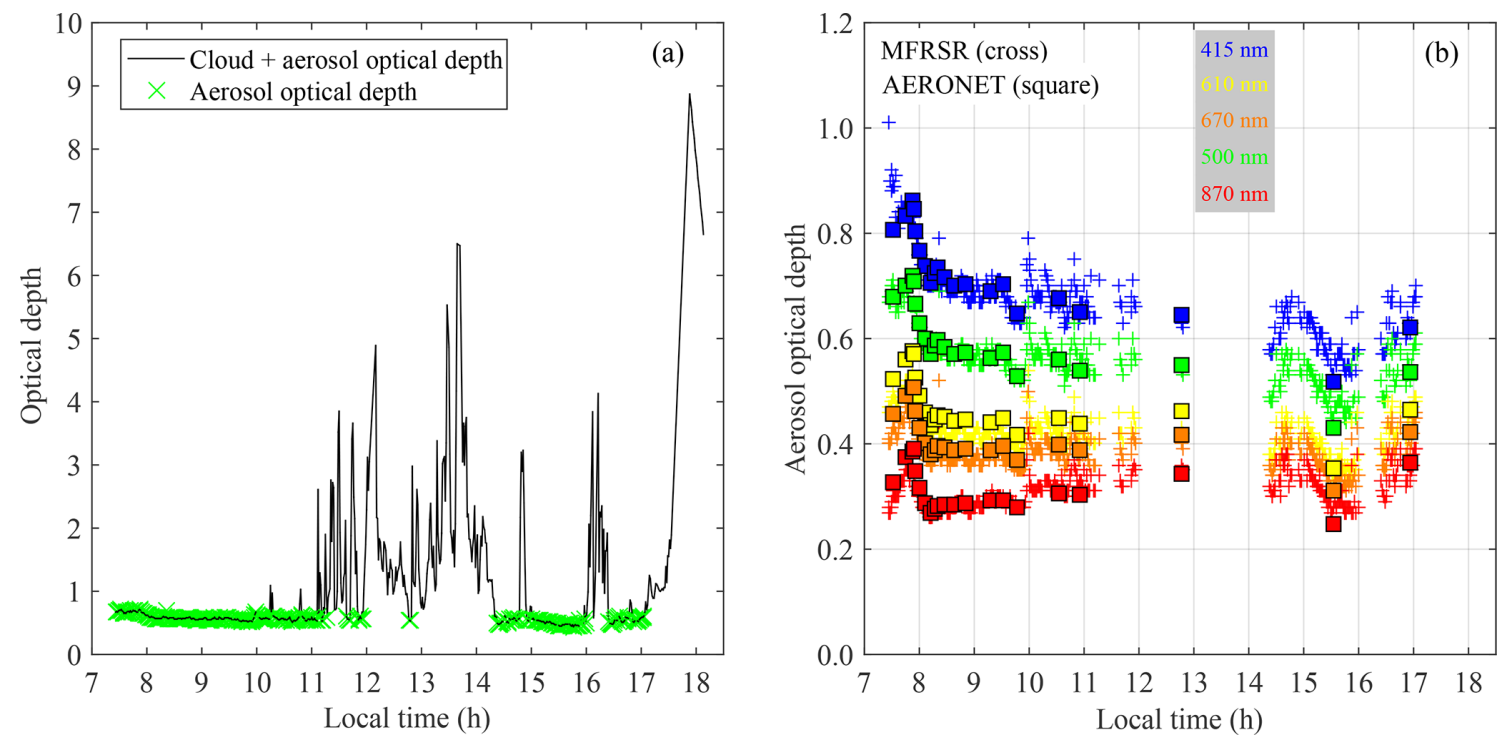

Figure 3. (a) Example of the cloud screening procedure applied to the MFRSR aerosol optical depth retrievals (22 November 2012). (b) Cloud screened diurnal cycle of multichannel aerosol optical depth from MFRSR compared with AOD retrievals from the AERONET Level 2.0 product.

lowest AOD $500 \mathrm{~nm}$ levels, ranging from $\approx 0.05$ to $\approx 0.20$. In a completely opposite scenario, during the biomass burning season (August to November), $\mathrm{AOD}_{500 \mathrm{~nm}}$ hardly goes down below 0.20 and values above 0.50 are quite frequent. During the transition periods, from background conditions to biomass burning (June to July) and from biomass burning to background conditions (December to February), AOD $_{500 \mathrm{~nm}}$ oscillated between typical background and biomass burning season values. Considering that the enhancement of $\mathrm{AOD}_{\lambda}$ during the biomass burning season across central Amazonia is dominated by increases in small particles (Eck et

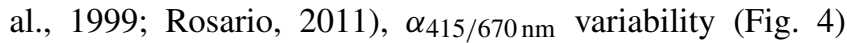
is consistent with the $\mathrm{AOD}_{500 \mathrm{~nm}}$ discussion; i.e. as the aerosol loading increases from July to the biomass burning months (August-November), $\alpha_{415 / 670 \mathrm{~nm}}$ also shows an enhancement. Ångström exponents ranging from 0.4 to 0.8 , which are dominant under background conditions, became rare throughout the biomass burning season and intermittent during the transition periods, a feature consistently described by the MFRSR and the AERONET Sun photometer. Similar results, for both $\mathrm{AOD}_{500 \mathrm{~nm} m}$ and $\alpha_{415 / 670 \mathrm{~nm}}$, were observed regarding 2015 (not shown here).

Figures 5 and 6 show scatter plots and statistic metrics (bias, RMSE, and correlation coefficient) comparing MFRSR and AERONET Sun photometer retrievals for 2012 and 2015, respectively. In general, there is a good agreement between both $\mathrm{AOD}_{\lambda}$ retrievals. However, non-negligible trends are seen, especially for 2012, and in particular for the lower and higher AOD edges. For low $\mathrm{AOD}_{\lambda}$ values, a systematic underestimation by MFRSR is observed for all channels, while for high $\mathrm{AOD}_{\lambda}$, the longer wavelength channels
(610 and $670 \mathrm{~nm}$ ) tend to underestimate AOD. The trends in 2015 are less evident, mainly for the low aerosol loading when compared with 2012. Nevertheless, overall the statistical metrics used to evaluate MFRSR retrievals performance against the AERONET Sun photometer suggest that, when it is not possible to perform calibration on high mountaintops, the extraterrestrial response calibration performed in central Amazonia has the reliability required to support consistent retrievals of AOD. The obtained RMSEs are lower than the estimated uncertainty for MFRSR $\mathrm{AOD}_{\lambda}$ retrievals (i.e. $\approx 0.02-\approx 0.03$, depending on the $I_{\mathrm{DN}, \lambda}$ uncertainty assumed) and slightly above the maximum uncertainty for the AERONET field instrument $(\approx 0.02)$.

Figure 7 compares Ångström exponents derived using AOD retrieved from the AERONET Sun photometer and MFRSR measurements, although comparisons are not as good as those observed for AOD, MFRSR results provide a consistent range of the Ångström exponent in respect to the AERONET results.

\section{Conclusions}

Does the pristine central Amazonian atmosphere provide successful extraterrestrial response calibration based on the Langley plot method? This question emerged from the challenge of maintaining regular calibration of a MFRSR dedicated to long-term retrieval of columnar aerosol optical properties in the central Amazon. To answer the question, the MFRSR was calibrated on site using the Langley plot method for two distinct and temporally distant years, 2012 and 2015, and subsequently applied to the retrieval of aerosol columnar 

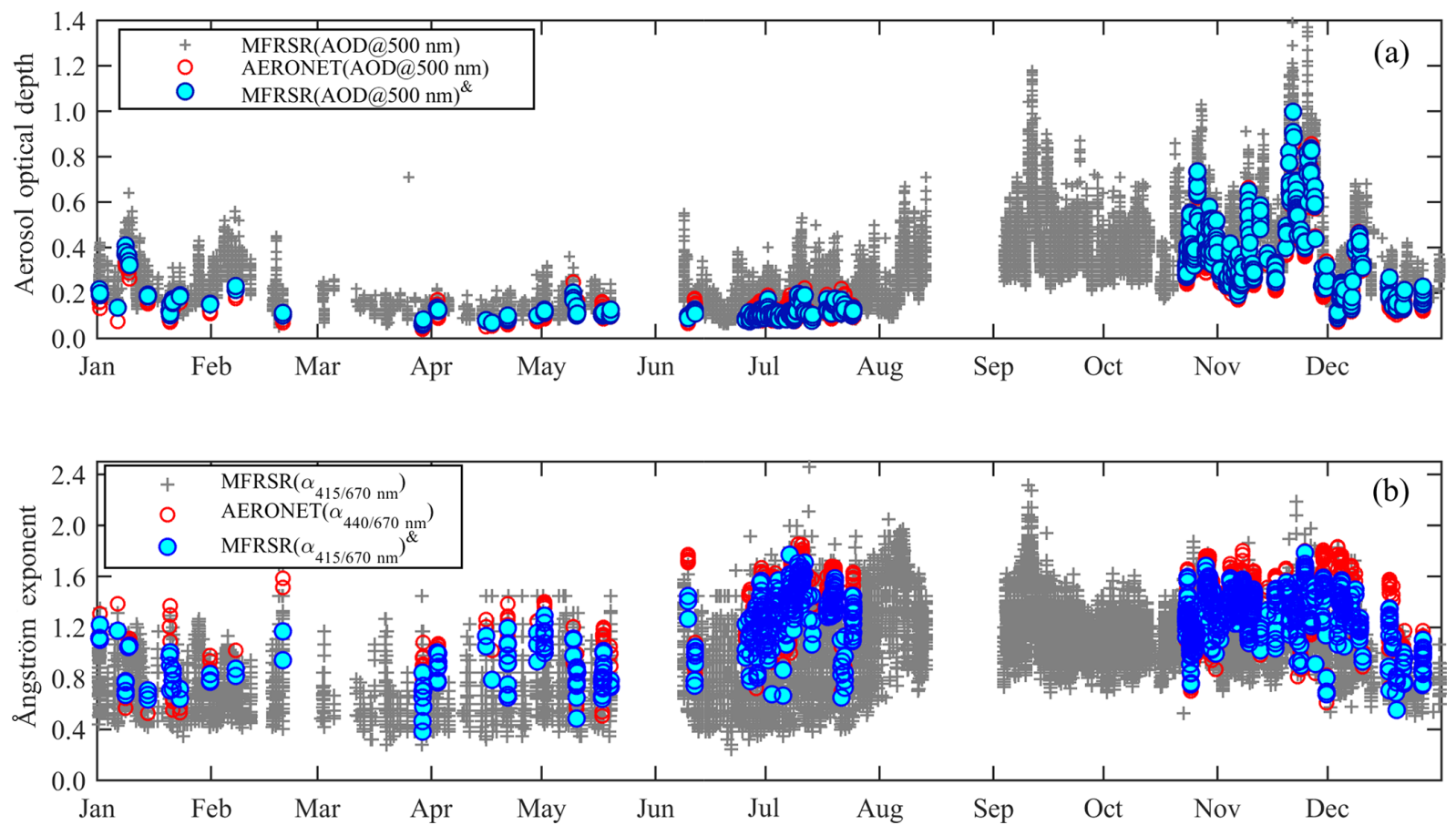

Figure 4. Seasonal variability of (a) aerosol optical depth and (b) the Ångström exponent (AE) in the visible spectrum region in central Amazonia for 2012. MFRSR (AOD@500 nm) represents MFRSR instantaneous AOD retrieval at 1 min rate; MFRSR (AOD@500 nm)\& represents only MFRSR AOD retrieved that have been collocated in time with AERONET Sun photometer AOD retrieval (AERONET

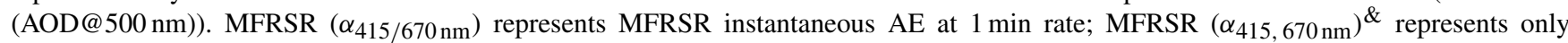

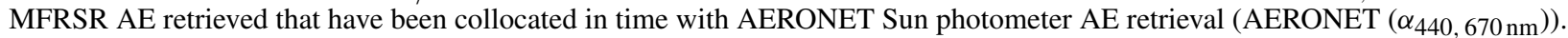
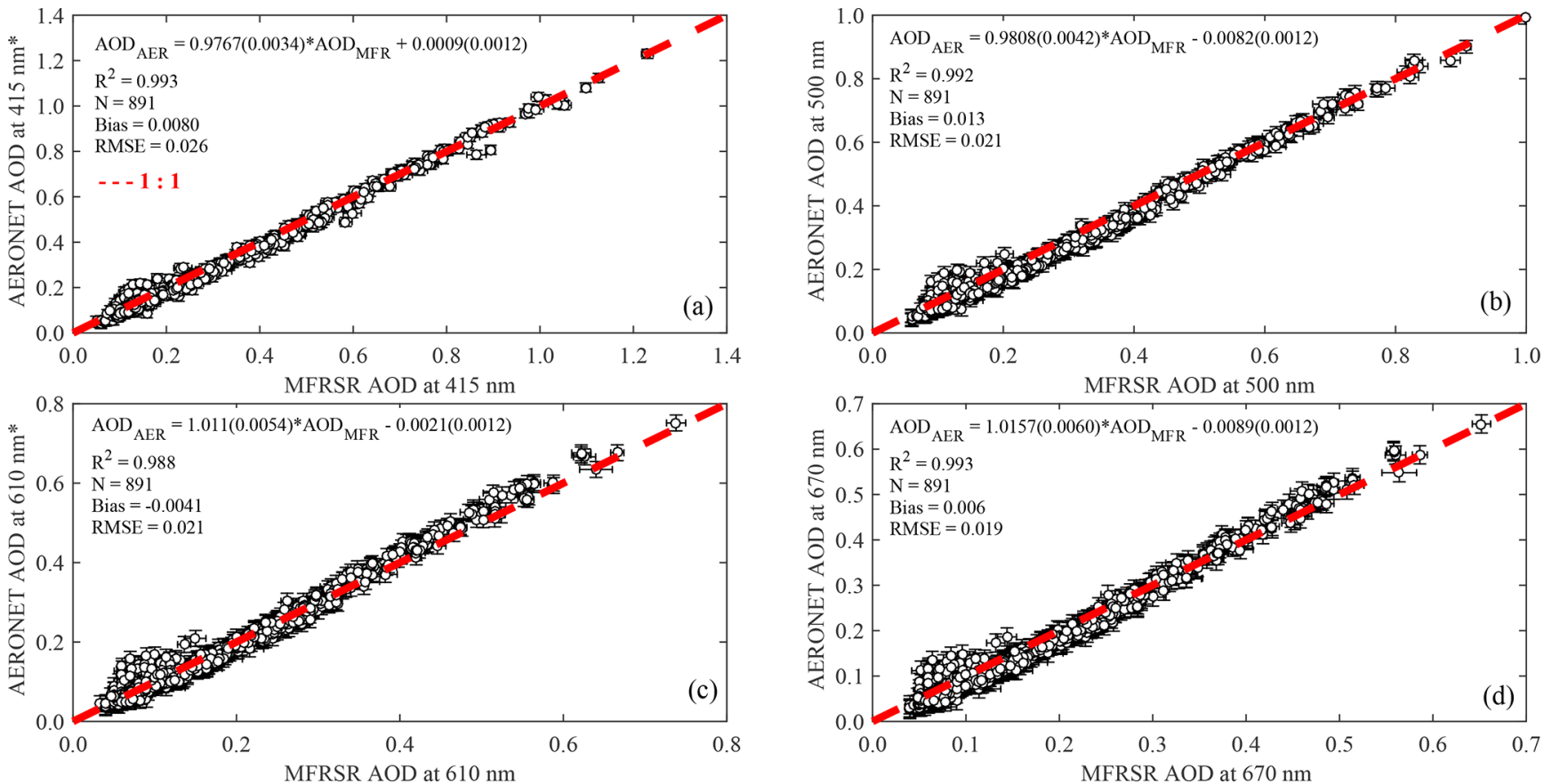

Figure 5. Spectral AOD retrieval from the on-site calibrated MFRSR as a function of AOD from the AERONET direct Sun product level 2.0 for 2012. The asterisk $\left(^{*}\right)$ indicates that the AOD at that wavelength was estimated using the Ångström exponent and the dashed red line represents the $1: 1$ line. 

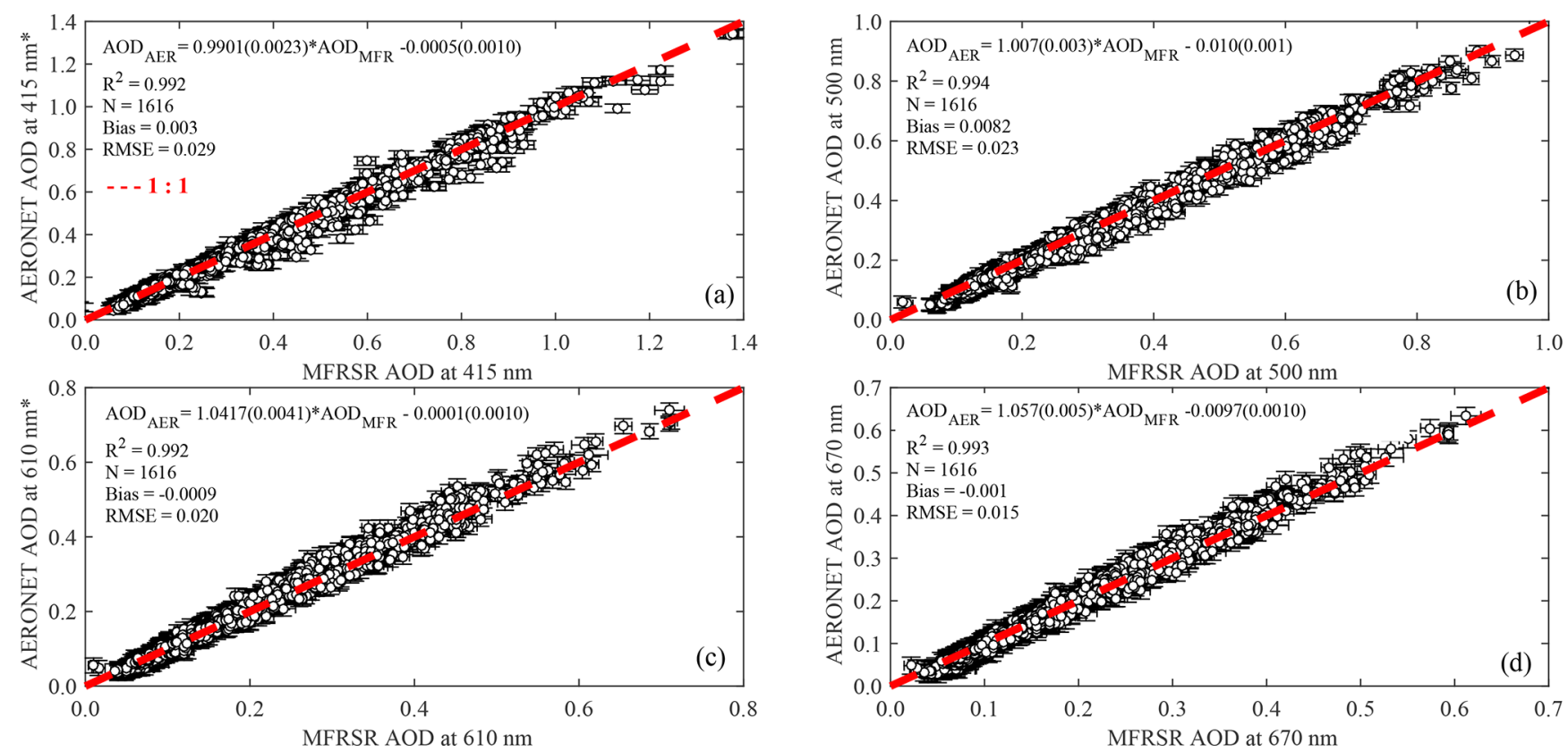

Figure 6. Spectral AOD retrieval from the on-site calibrated MFRSR as a function of AOD from the AERONET direct Sun product level 2.0 for 2015 . The asterisk $\left(^{*}\right)$ indicates that the AOD at that wavelength was estimated using the Angström exponent and the red dashed line represents the $1: 1$ line.
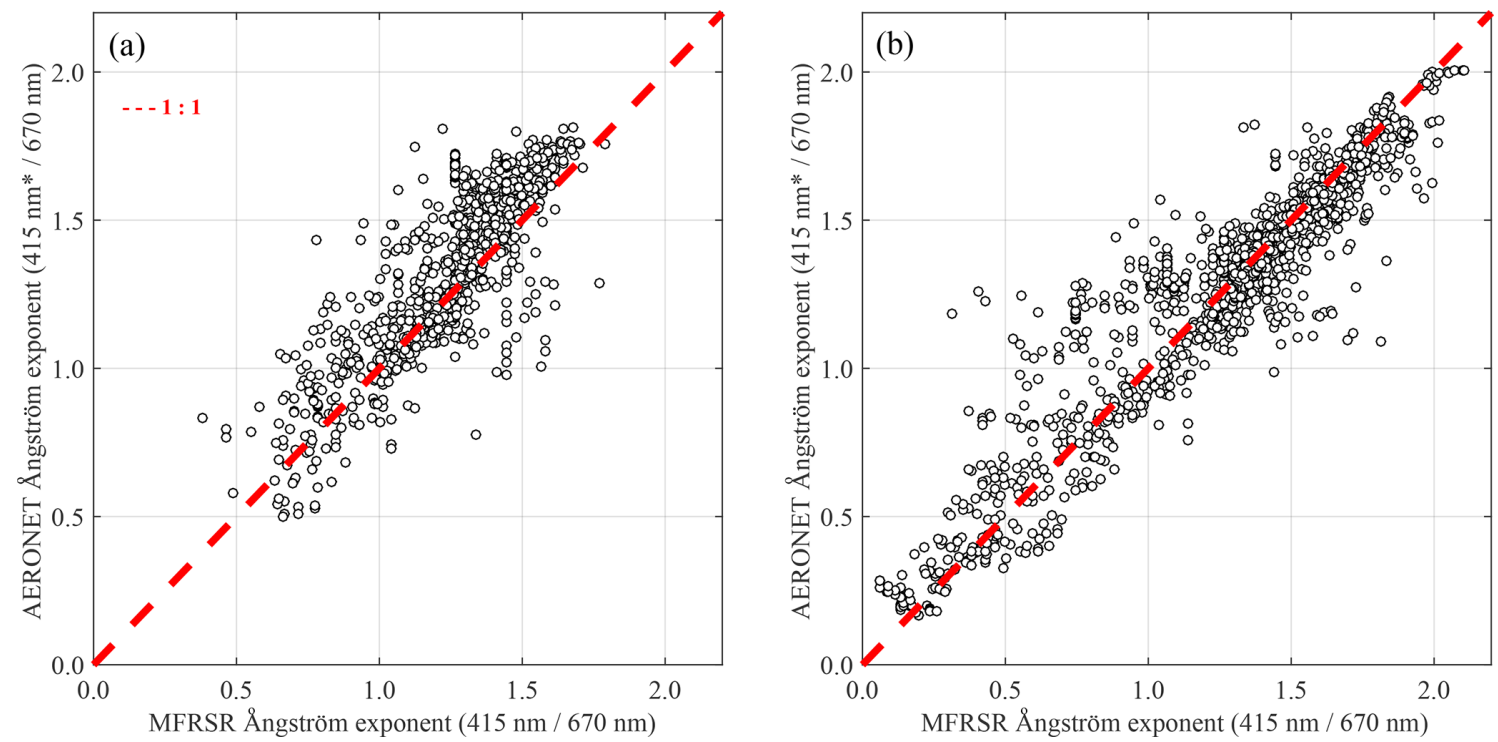

Figure 7. The Ångström exponent (AE) for the visible spectrum derived using AOD at 415 and $670 \mathrm{~nm}$ from the on-site calibrated MFRSR as a function of AE derived from AOD at $415 \mathrm{~nm}^{*}$ and $670 \mathrm{~nm}$ corresponding to the AERONET direct Sun product level 2.0 for (a) 2012 and (b) 2015. The asterisk $(*)$ indicates that AERONET AOD at $415 \mathrm{~nm}$ was estimated using AE since this channel is not present in network Sun photometers. The red dashed line represents $1: 1$ line.

optical properties, i.e. AOD and Ångström exponent (AE). Retrievals were evaluated against direct Sun inversion products (Level 2.0) from a collocated Cimel Sun photometer belonging to AERONET. Results obtained show that onsite calibration using the Langley plot method, under pristine Amazonian conditions, is able to provide extraterres- trial response with relative uncertainties varying from $\approx 0.4$ to $\approx 1.0 \%$ in MFRSR visible channels. The worst estimator (air mass $=1$ ) for absolute uncertainty in retrieved $\mathrm{AOD}_{\lambda}$ can vary from $\approx 0.03$ to $\approx 0.02$, depending on the assumption regarding the uncertainty assumed for MFRSR direct normal irradiance measured at the surface $\left(I_{\mathrm{DN}}, \lambda\right)$, which 
in the literature varies from $1.5 \%$ to $3.0 \%$. All root mean square errors (RMSEs), obtained from the comparison of MFRSR retrievals against the AERONET Sun photometer $\mathrm{AOD}_{\lambda}$ for coincident channels ( 500 and $670 \mathrm{~nm}$ ), were lower $(<0.025)$ than the estimated MFRSR $\mathrm{AOD}_{\lambda}$ uncertainties $(0.03)$ and close to the AERONET field Sun photometers $(\approx 0.02)$. Using the point of view of the question posed, these results suggest that on-site calibration in pristine central Amazonian conditions is able to provide consistent retrieval of $\mathrm{AOD}_{\lambda}$. Another relevant aspect of the results provided by the MFRSR, due to its high measurement frequency (1 min), is the improvement of the statistics of AOD under cloudy conditions, which is critical for Amazonia. The current AERONET Sun photometer statistics are expected to be biased to cloudless sky conditions, which are dominant during the morning and the dry season.

Data availability. The underlying research data can be accessed upon request to the corresponding author (Nilton E. Rosário, nrosario@unifesp.br).

Supplement. The supplement related to this article is available online at: https://doi.org/10.5194/amt-12-921-2019-supplement.

Author contributions. TP and HMJB conceived and planned the experimental site, operated the instrumentation, and, along with BB, performed the data organization and primary processing. MAY assisted with the calibration procedure discussions and analysis, including theoretical and technical issues. TS and NER processed the experimental data, performed the analysis, and designed the figures. NER wrote the manuscript with input from all authors.

Competing interests. The authors declare that they have no conflict of interest.

Special issue statement. This article is part of the special issue "Observations and Modeling of the Green Ocean Amazon (GoAmazon2014/5) (ACP/AMT/GI/GMD inter-journal SI)". It is not associated with a conference.

Acknowledgements. The authors would like to thank EMBRAPA, INPA, and the LBA Central office for logistical support. Special thanks to Marcelo Rossi, Victor Souza, and Jocivaldo Souza at EMBRAPA, and to Ruth Araujo, Roberta Souza, Bruno Takeshi, and Glauber Cirino from LBA. Henrique Barbosa acknowledges the financial support from FAPESP Research Program on Global Climate Change under research grants 2008/58100-1, 2012/161001, 2013/50510-5, 2013/05014-0, and 2017/17047-0. Theotonio Pauliquevis acknowledges the financial support from CNPq research grant 458017/2013-2. Boris Barja acknowledges the financial support of CAPES project A016-2013 on the programme
Science without Frontiers and the SAVERNET project.

Edited by: Piet Stammes

Reviewed by: Joseph Michalsky and one anonymous referee

\section{References}

Alexandrov, M. D., Lacis, A. A., Carlson, B. E., and Cairns, B.: Remote Sensing of Atmospheric Aerosols and Trace Gases by Means of Multifilter Rotating Shadowband Radiometer. Part II: Climatological Applications, J. Atmos. Sci., 59, 544-566, https://doi.org/10.1175/15200469(2002)059<0544:RSOAAA>2.0.CO;2, 2002.

Alexandrov, M. D., Marshak, A., Cairns, B., Lacis, A. A., and Carlson, B. E.: Automated cloud screening algorithm for MFRSR data, Geophys. Res. Lett., 31, L04118, https://doi.org/10.1029/2003GL019105, 2004.

Alexandrov, M. D., Kiedron, P., Michalsky, J. J., Hodges, G., Flynn, C. J., and Lacis, A. A.: Optical depth measurements by shadowband radiometers and their uncertainties, Appl. Optics, 46, 80278038, https://doi.org/10.1364/AO.46.008027, 2007.

Andreae, M. O., Rosenfeld, D., Artaxo, P., Costa, A. A., Frank, G. P., Longo, K. M., and Silva-Dias, M. A.F.: Smoking Rain Clouds over the Amazon, Science, 303, 1337-1342, https://doi.org/10.1126/science.1092779, 2004.

Artaxo, P., Fernandas, E. T., Martins, J. V., Yamasoe, M. A., Hobbs, P. V., Maenhaut, W., Longo, K. M., and Castanho, A.: 10 Largescale aerosol source apportionment in Amazonia, J. Geophys. Res., 103, 31837-31847, https://doi.org/10.1029/98JD02346, 1998.

Augustine, J. A., Cornwall, C., Hodges, G., Long, C. N., Medina, C., and DeLuisi, J. J.: An automated method of MFRSR calibration for aerosol optical depth analysis with application to an Asian dust outbreak over the U.S., J. Appl. Meteorol., 4226642277, 2003.

Augustine, J. A., Hodges, G. B., Dutton, E. G., Michalsky, J. J., and Cornwall, C. R.: An aerosol optical depth climatology for NOAA's national surface radiation budget network (SURFRAD), J. Geophys. Res., 113, D11204, https://doi.org/10.1029/2007JD009504, 2008.

Avissar, R., Silva Dias, P. L., Silva Dias, M. A. F., and Nobre, C.: The Large-Scale Biosphere-Atmosphere Experiment in Amazonia (LBA): Insights and future research needs, J. Geophys. Res., 107, 8086, https://doi.org/10.1029/2002JD002704, 2002.

Barbosa, H. M. J., Barja, B., Pauliquevis, T., Gouveia, D. A., Artaxo, P., Cirino, G. G., Santos, R. M. N., and Oliveira, A. B.: A permanent Raman lidar station in the Amazon: description, characterization, and first results, Atmos. Meas. Tech., 7, 1745-1762, https://doi.org/10.5194/amt-7-1745-2014, 2014.

Ben-Ami, Y., Koren, I., Rudich, Y., Artaxo, P., Martin, S. T., and Andreae, M. O.: Transport of North African dust from the Bodélé depression to the Amazon Basin: a case study, Atmos. Chem. Phys., 10, 7533-7544, https://doi.org/10.5194/acp10-7533-2010, 2010.

Bovensmann, H., Burrows, J. P., Buchwitz, M., Frerick, J., Noël, S., Rozanov, V. V., Chance, K. V., and Goede, A. P. H.: SCIAMACHY: Mission Objectives and Measurement Modes, 
J. Atmos. Sci., 56,127-150, https://doi.org/10.1175/15200469(1999)056<0127:SMOAMM>2.0.CO;2, 1999.

Chen, M., Davis, J., Tang, H., Ownby, C., and Gao, W.: The calibration methods for Multi-Filter Rotating Shadowband Radiometer: a review, Front. Earth Sci., 7, 257-270, https://doi.org/10.1007/s11707-013-0368-9, 2013

de Sá, S. S., Palm, B. B., Campuzano-Jost, P., Day, D. A., Hu, W., Isaacman-VanWertz, G., Yee, L. D., Brito, J., Carbone, S., Ribeiro, I. O., Cirino, G. G., Liu, Y., Thalman, R., Sedlacek, A., Funk, A., Schumacher, C., Shilling, J. E., Schneider, J., Artaxo, P., Goldstein, A. H., Souza, R. A. F., Wang, J., McKinney, K. A., Barbosa, H., Alexander, M. L., Jimenez, J. L., and Martin, S. T.: Urban influence on the concentration and composition of submicron particulate matter in central Amazonia, Atmos. Chem. Phys., 18, 12185-12206, https://doi.org/10.5194/acp-18-121852018, 2018.

di Sarra, A., Sferlazzo, D., Meloni, D., Anello, F., Bommarito, C., Corradini, S., Silvestri, L. D., Iorio, T. D., Monteleone, F., Pace, G., Piacentino, S., and Pugnaghi, S.: Empirical correction of multifilter rotating shadowband radiometer (MFRSR) aerosol optical depths for the aerosol forward scattering and development of a long-term integrated MFRSRCimel dataset at Lampedusa, Appl. Optics, 54, 2725-2737, https://doi.org/10.1364/AO.54.002725, 2015.

Eck, T. F., Holben, B. N., Reid, J. S., Dubovik, O., Smirnov, A., O'Neill, N. T., Slutsker, I., and Kinne, S.: Wavelength dependence of the optical depth of biomass burning, urban, and desert dust aerosols, J. Geophys. Res., 104, 31333-31349, https://doi.org/10.1029/1999JD900923, 1999.

Forgan, B. W.: Sun photometer calibration by the ratio-langley method, in: Baseline atmospheric program (Australia) 1986, edited by: Forgan, B. W. and Fraser, P. J., Bureau of Meteorology, Melbourne, Australia, 22-26, 1988.

Forgan, B. W.: General method for calibrating Sun photometers, Appl. Optics, 33, 4841-4850, https://doi.org/10.1364/AO.33.004841, 1994.

Gouveia, D. A., Barja, B., Barbosa, H. M. J., Seifert, P., Baars, H., Pauliquevis, T., and Artaxo, P.: Optical and geometrical properties of cirrus clouds in Amazonia derived from 1 year of groundbased lidar measurements, Atmos. Chem. Phys., 17, 3619-3636, https://doi.org/10.5194/acp-17-3619-2017, 2017.

Harrison, L. and Michalsky, J.: Objective algorithms for the retrieval of optical depths from ground-based measurements, Appl. Optics, 33, 5126-5132, https://doi.org/10.1364/AO.33.005126, 1994.

Harrison, L., Michalsky, J., and Berndt, J.: Automated multifilter rotating shadow-band radiometer: an instrument for optical depth and radiation measurements, Appl. Optics, 33, 5118-5125, https://doi.org/10.1364/AO.33.005118, 1994.

Hoff, R. M. and Christopher, S. A.: Remote Sensing of Particulate Pollution from Space: Have We Reached the Promised Land?, J. Air Waste Manage., 59, 645-675, https://doi.org/10.3155/1047-3289.59.6.645, 2009.

Holben, B., Eck, T., Slutsker, I., Tanré, D., Buis, J., Setzer, A., Vermote, E., Reagan, J., Kaufman, Y., Nakajima, T., Lavenu, F., Jankowiak, I., and Smirnov, A.: AERONET-A Federated Instrument Network and Data Archive for Aerosol Characterization, Remote Sens. Environ., 66, 1-16, https://doi.org/10.1016/S00344257(98)00031-5, 1998.
Iqbal, M.: An Introduction to Solar Radiation, Academic Press, San Diego, California, 1983.

Irvin, J. A. and Quickenden, T. I.: Linear least squares treatment when there are errors in both $\mathrm{x}$ and $\mathrm{y}$, J. Chem. Educ., 60, 711, https://doi.org/10.1021/ed060p711, 1983.

Kassianov, E., Barnard, J., Berg, L. K., Long, C. N., and Flynn, C.: Shortwave spectral radiative forcing of cumulus clouds from surface observations, Geophys. Res. Lett., 38, L07801, https://doi.org/10.1029/2010GL046282, 2011.

Kasten, F. and Young, A. T.: Revised optical air mass tables and approximation formula, Appl. Optics, 28, 4735-4738, https://doi.org/10.1364/AO.28.004735, 1989.

Kaufman, Y. J., Tanre, D., and Boucher, O.: A satellite view of aerosols in the climate system, Nature, 419, 215-223, 2002.

Koren, I., Kaufman, Y. J., Washington, R., Todd, M. C., Rudich, Y., Martins, J. V., and Rosenfeld, D.: The Bodélé depression: a single spot in the Sahara that provides most of the mineral dust to the Amazon forest, Environ. Res. Lett., 1, 014005, https://doi.org/10.1088/1748-9326/1/1/014005, 2006.

Kuhn, U., Ganzeveld, L., Thielmann, A., Dindorf, T., Schebeske, G., Welling, M., Sciare, J., Roberts, G., Meixner, F. X., Kesselmeier, J., Lelieveld, J., Kolle, O., Ciccioli, P., Lloyd, J., Trentmann, J., Artaxo, P., and Andreae, M. O.: Impact of Manaus City on the Amazon Green Ocean atmosphere: ozone production, precursor sensitivity and aerosol load, Atmos. Chem. Phys., 10, 9251-9282, https://doi.org/10.5194/acp-10-9251-2010, 2010.

Levelt, P. F., van den Oord, G. H. J., Dobber, M. R., Malkki, A., Visser, H., de Vries, J., Stammes, P., Lundell, J. O. V., and Saari, H.: The ozone monitoring instrument, IEEE T. Geosci. Remote, 44, 1093-1101, https://doi.org/10.1109/TGRS.2006.872333, 2006.

Levy, R. C., Remer, L. A., Kleidman, R. G., Mattoo, S., Ichoku, C., Kahn, R., and Eck, T. F.: Global evaluation of the Collection 5 MODIS dark-target aerosol products over land, Atmos. Chem. Phys., 10, 10399-10420, https://doi.org/10.5194/acp-10-103992010, 2010.

Martin, S. T., Artaxo, P., Machado, L. A. T., Manzi, A. O., Souza, R. A. F., Schumacher, C., Wang, J., Andreae, M. O., Barbosa, H. M. J., Fan, J., Fisch, G., Goldstein, A. H., Guenther, A., Jimenez, J. L., Pöschl, U., Silva Dias, M. A., Smith, J. N., and Wendisch, M.: Introduction: Observations and Modeling of the Green Ocean Amazon (GoAmazon2014/5), Atmos. Chem. Phys., 16, 47854797, https://doi.org/10.5194/acp-16-4785-2016, 2016.

Mazzola, M., Lanconelli, C., Lupi, A., Busetto, M., Vitale, V., and Tomasi, C.: Columnar aerosol optical properties in the Po Valley, Italy, from MFRSR data, J. Geophys. Res., 115, D17206, https://doi.org/10.1029/2009JD013310, 2010.

Menon, S.: Current Uncertainties In Assessing Aerosol Effects On Climate, Annu. Rev. Env. Resour., 29, 1-30, https://doi.org/10.1146/annurev.energy.29.063003.132549, 2004.

Michalsky, J. and LeBaron, B.: Fifteen-year aerosol optical depth climatology for Salt Lake City, J. Geophys. Res.-Atmos., 118, 3271-3277, https://doi.org/10.1002/jgrd.50329, 2013.

Michalsky, J., Denn, F., Flynn, C., Hodges, G., Kiedron, P., Koontz, A., Schlemmer, J., and Schwartz, S. E.: Climatology of aerosol optical depth in north-central Oklahoma: 1992-2008, J. Geophys. Res., 115, D07203, https://doi.org/10.1029/2009JD012197, 2010. 
Michalsky, J. J., Liljegren, J. C., and Harrison, L. C.: A comparison of Sun photometer derivations of total column water vapor and ozone to standard measures of same at the Southern Great Plains Atmospheric Radiation Measurement site, J. Geophys. Res., 100, 25995-26003, https://doi.org/10.1029/95JD02706, 1995.

Michalsky, J. J., Schlemmer, J. A., Berkheiser, W. E., Berndt, J. L., Harrison, L. C., Laulainen, N. S., Larson, N. R., and Barnard, J. C.: Multiyear measurements of aerosol optical depth in the Atmospheric Radiation Measurement and Quantitative Links programs, J. Geophys. Res., 106, 12099-12107, https://doi.org/10.1029/2001JD900096, 2001.

Min, Q. and Harrison, L. C.: Cloud properties derived from surface MFRSR measurements and comparison with GOES results at the ARM SGP Site, Geophys. Res. Lett., 23, 1641-1644, https://doi.org/10.1029/96GL01488, 1996.

Moran-Zuloaga, D., Ditas, F., Walter, D., Saturno, J., Brito, J., Carbone, S., Chi, X., Hrabe de Angelis, I., Baars, H., Godoi, R. H. M., Heese, B., Holanda, B. A., Lavric, J. V., Martin, S. T., Ming, J., Pöhlker, M. L., Ruckteschler, N., Su, H., Wang, Y., Wang, Q., Wang, Z., Weber, B., Wolff, S., Artaxo, P., Pöschl, U., Andreae, M. O., and Pöhlker, C.: Long-term study on coarse mode aerosols in the Amazon rain forest with the frequent intrusion of Saharan dust plumes, Atmos. Chem. Phys., 18, 10055-10088, https://doi.org/10.5194/acp-18-10055-2018, 2018.

O’Neill, N. T., McArthur, L. J. B., and Strawbridge, K. B.: Recent progress in the remote sensing of aerosols, Physics in Canada, 61, 235-241, 2005.

Roberts, G. C., Andreae, M. O., Zhou, J., and Artaxo, P.: Cloud condensation nuclei in the Amazon Basin: "marine" conditions over a continent?, Geophys. Res. Lett., 28, 2807-2810, https://doi.org/10.1029/2000GL012585, 2001.

Rosario, N.: Variability of aerosol optical properties over South America and the impacts of direct radiative effect of aerosols from biomass burning, $\mathrm{PhD}$ thesis, Institute of Astronomy, Geophysics and Atmospheric Sciences, University of São Paulo, Brazil, 2011.

Rosario, N. E., Yamasoe, M. A., and Longo, K. M.: Aerosol Optical Depth and Ångström Coefficient retrievals over the Amazon Forest during 2007 biomass burning season, AIP Conf. Proc., 1100, 494-497, https://doi.org/10.1063/1.3117029, 2009.

Rosário, N. M. E., Yamasoe, M. A., Sayao, A., and Siqueira, R.: Multifilter rotating shadowband radiometer calibration for spectral aerosol optical depth retrievals over Sao Paulo City, Brazil, Appl. Optics, 47, p. 1171, 2008.

Satheesh, S. K. and Srinivasan, J.: A method to infer short wave absorption due to aerosols using satellite remote sensing, Geophys. Res. Lett., 32, L13814, https://doi.org/10.1029/2005GL023064, 2005.

Schafer, J. S., Eck, T. F., Holben, B. N., Artaxo, P., and Duarte, A. F.: Characterization of the optical properties of atmospheric aerosols in Amazonia from long-term AERONET monitoring (1993-1995 and 1999-2006), J. Geophys. Res., 113, D04204, https://doi.org/10.1029/2007JD009319, 2008

Schmid, B. and Wehrli, C.: Comparison of the sun photometer calibration by use of the Langley technique and the standard lamp, Appl. Optics, 34, 4500-4512, 1995.
Schneider, M., Romero, P. M., Hase, F., Blumenstock, T., Cuevas, E., and Ramos, R.: Continuous quality assessment of atmospheric water vapour measurement techniques: FTIR, Cimel, MFRSR, GPS, and Vaisala RS92, Atmos. Meas. Tech., 3, 323338, https://doi.org/10.5194/amt-3-323-2010, 2010.

Shaw, G. E.: Sun Photometry, B. Am. Meteorol., Soc., 64, 4-10, https://doi.org/10.1175/15200477(1983)064<0004:SP>2.0.CO;2, 1983.

Shaw, G. E., Reagan, J. A., and Herman, B. M.: Investigations of Atmospheric Extinction Using Direct Solar Radiation Measurements Made with a Multiple Wavelength Radiometer, J. Appl. Meteorol., 12, 374-380, 1973.

Silva Dias, M. A. F., Rutledge, S., Kabat, P., Silva Dias, P. L., Nobre, C., Fisch, G., Dolman, A. J., Zipser, E., Garstang, M., Manzi, A. O., Fuentes, J. D., Rocha, H. R., Marengo, J., Plana-Fattori, A., Sá, L. D. A., Alvalá, R. C. S., Andreae, M. O., Artaxo, P., Gielow, R., and Gatti, L.: Cloud and rain processes in a biosphereatmosphere interaction context in the Amazon Region, J. Geophys. Res., 107, 8072, https://doi.org/10.1029/2001JD000335, 2002.

Sinyuk, A., Holben, B. N., Smirnov, A., Eck, T. F., Slutsker, I., Schafer, J. S., Giles, D. M., and Sorokin, M.: Assessment of error in aerosol optical depth measured by AERONET due to aerosol forward scattering, Geophys. Res. Lett., 39, L23806, https://doi.org/10.1029/2012GL053894, 2012.

Staehelin, J., Schill, H., Hoegger, B., Viatte, P., Levrat, G., and Gamma, A.: Total ozone observation by sun photometry at Arosa, Switzerland, Opt. Eng., 34, 1977-1986, 1995.

Tomasi, C. and Petkov, B. H.: Calculations of relative optical air masses for various aerosol types and minor gases in Arctic and Antarctic atmospheres, J. Geophys. Res.-Atmos., 119, 13631385, https://doi.org/10.1002/2013JD020600, 2014.

van Donkelaar, A., Martin, R. V., Brauer, M., Kahn, R., Levy, R., Verduzco, C., and Villeneuve, P. J.: Global Estimates of Ambient Fine Particulate Matter Concentrations from Satellite-Based Aerosol Optical Depth: Development and Application, Environ. Health Persp., 847-855, https://doi.org/10.1289/ehp.0901623, 2010.

van Donkelaar, A., Martin, R. V., Spurr, R. J. D., Drury, E., Remer, L. A., Levy, R. C., and Wang, J.: Optimal estimation for global ground-level fine particulate matter concentrations, J. Geophys. Res.-Atmos., 118, 5621-5636, https://doi.org/10.1002/jgrd.50479, 2013.

Yamasoe, M. A. and do Rosario, N. E.: Changes in solar radiation partitioning reaching the surface due to biomass burning aerosol particles in the Amazon Basin, AIP Conf. Proc., 1100, 657-660, https://doi.org/10.1063/1.3117072, 2009.

Yamasoe, M. A., do Rosario, N. M. E., Leiva, E. A., Costa, T. S., and Braghiere, R. K.: Aerosol optical properties, downward solar irradiance and Ozone concentrations measured at Humaitá, AM, during the biomass burning season of 2012, in: Changing chemistry in a changing world: Scientific Program, International Commission on Atmospheric Chemistry and Global Pollution, Bremen, 2014. 